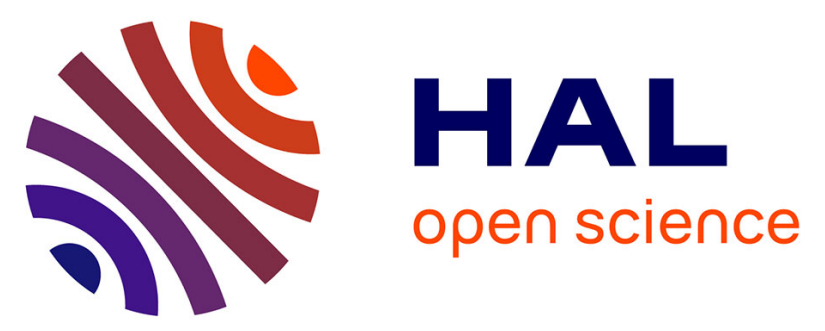

\title{
Mechanical Thrombectomy in Acute Ischemic Stroke Patients under Venoarterial Extracorporeal Membrane Oxygenation
}

Loic Le Guennec, Matthieu Schmidt, Frédéric Clarençon, Ahmed Mohamed Elhfnawy, Flore Baronnet, Michel Kalamarides, Guillaume Lebreton, Charles-Edouard Luyt

\section{To cite this version:}

Loic Le Guennec, Matthieu Schmidt, Frédéric Clarençon, Ahmed Mohamed Elhfnawy, Flore Baronnet, et al.. Mechanical Thrombectomy in Acute Ischemic Stroke Patients under Venoarterial Extracorporeal Membrane Oxygenation. Journal of Neurointerventional Surgery, 2020, 12 (5), pp.486-488. 10.1136/neurintsurg-2019-015407 . hal-03003478

\section{HAL Id: hal-03003478 \\ https://hal.sorbonne-universite.fr/hal-03003478}

Submitted on 13 Nov 2020

HAL is a multi-disciplinary open access archive for the deposit and dissemination of scientific research documents, whether they are published or not. The documents may come from teaching and research institutions in France or abroad, or from public or private research centers.
L'archive ouverte pluridisciplinaire HAL, est destinée au dépôt et à la diffusion de documents scientifiques de niveau recherche, publiés ou non, émanant des établissements d'enseignement et de recherche français ou étrangers, des laboratoires publics ou privés. 


\title{
Mechanical Thrombectomy in Acute Ischemic Stroke Patients under Venoarterial Extracorporeal Membrane Oxygenation
}

\author{
Loïc Le Guennec1,2, Matthieu Schmidt1,2,3, Frédéric Clarençon 2,4, Ahmed \\ Mohamed Elhfnawy2,4, Flore Baronnet2,5 , Michel Kalamarides2,6, Guillaume \\ Lebreton ${ }^{2,7}$, and Charles-Edouard Luyt1,2,3
}

1Service de Réanimation, Institut de Cardiologie, Groupe Hospitalier Pitié-Salpêtrière, Assistance PubliqueHôpitaux de Paris, Paris, France;

2Sorbonne Universités, UPMC Université Paris 06

3INSERM, UMRS_1166-ICAN Institute of Cardiometabolism and Nutrition, Paris, France;

4Service de Neuroradiologie, Groupe Hospitalier Pitié-Salpêtrière, Assistance Publique-Hôpitaux de Paris, Paris, France;

5Service de Neurologie vasculaire, Groupe Hospitalier Pitié-Salpêtrière, Assistance Publique-Hôpitaux de Paris, Paris, France;

6Service de Neurochirurgie, Groupe Hospitalier Pitié-Salpêtrière, Assistance Publique-Hôpitaux de Paris, Paris, France;

7Service de Chirurgie Thoracique et Cardiovasculaire, Institut de Cardiologie, Groupe Hospitalier PitiéSalpêtrière, Assistance Publique-Hôpitaux de Paris, Paris, France

Corresponding author: Loïc LE GUENNEC, MD - Service de Réanimation Hôpital Pitié Salpêtrière, 47, boulevard de l'Hôpital 75013 Paris, France Phone: 33.1.42.16.38.16 Fax: 33.1.42.16.38.17 e-mail: loic.leguennec@aphp.fr

Author Contributions: All authors wrote the initial manuscript and approved the final version.

Conflicts of Interest and Source Funding: F. Clarençon reports conflict of interest with Medtronic, Guerbet, Balt Extrusion (payment for readings), Codman Neurovascular (core lab). The other authors have no conflicts of interest to declare in relationship with this manuscript.

Word count: $1368 / 3000$

Abstract word count: 69 / 250

Figure: $2 / 4$ 


\section{SUMMARY}

Use of venoarterial extracorporeal membrane oxygenation (VA-ECMO) in adult to treat refractory cardiogenic shock has increased in recent years, and ischemic stroke is the most frequent VA-ECMO-induced cerebrovascular complication. No adult case of mechanical thrombectomy (MT) has been reported. We describe herein two adult patients on VA-ECMO with acute ischemic stroke, successfully treated with MT, and discuss feasibility and safety of such procedure.

\section{BACKGROUND}

Venoarterial extracorporeal membrane oxygenation (VA-ECMO) is used to provide circulatory support in patients with refractory cardiogenic shock ${ }^{12}$. Ischemic stroke is among the most frequent complications occurring in VA-ECMO-treated patients s.5. $^{3-}$ Due to the increased risk of secondary hemorrhagic transformation, the need for curative anticoagulation, and the ECMO-related hemostasis disorders, thrombolysis for acute ischemic stroke in patients on ECMO is theoretically contra-indicated, and has never been reported so far in an adult patient. We describe herein two adult patients from our tertiary care center, with acute ischemic stroke occurring while on VA-ECMO support, successfully treated by mechanical thrombectomy (MT).

\section{CASES PRESENTATION}

The first case was a 51-year-old man with a history of ischemic dilated cardiomyopathy admitted to the intensive care unit (ICU) for cardiogenic shock. Despite optimal medical treatment, his condition worsened and a femoro-femoral VA-ECMO was implanted in the left groin under local anesthesia. Five days after VAECMO implantation, he presented a sudden right hemiplegia with aphasia with an initial national institute of health stroke scale (NIHSS) of 18. CT-angiography (CTA) was performed, since ECMO is an MRI-incompatible device, and showed left middle cerebral artery (MCA) M1 segment occlusion. MT was urgently performed via a right femoral artery access, using a Solitaire stent retriever (Medtronic, Irvine, CA). Time to groin puncture was 4 hours, with a successful result. Modified Thrombolysis In Cerebral Infarction ( $\mathrm{mTICl}$ ) score was at 3 at the end of the procedure. Brain CT scan performed $24 \mathrm{~h}$ after recanalization showed no sign of hemorrhagic transformation. Patient's cardiac condition progressively improved, and VA-ECMO was removed on day 9. Ten day after the ischemic stroke, he was discharged from the ICU and transferred in the cardiology department. At this time, he only presented a slight aphasia, with a Rankin score of 1 . One year later he had normal neurological examination with a Rankin score of 0.

The second case was a 35 year-old man, who was admitted for cardiogenic shock complicating acute myocardial infarction. Coronary angiography showed proximal left anterior descending artery occlusion, that was successfully stented. At the end of the procedure, he developed refractory cardiogenic shock requiring implantation of a peripheral, left femoro-femoral ECMO, and a sudden left hemiplegia with an 
initial NIHSS of 24. CTA showed distal right MCA occlusion. After multidisciplinary team discussion, MT was performed via the right femoral artery, using a Solitaire stent retriever. Time to groin puncture was 6.5 hours, with a successful result (Figure $1 ; \mathrm{A}, \mathrm{B}$ ). $\mathrm{mTICl}$ score was at 3 at the end of the procedure. Brain CT performed $24 \mathrm{~h}$ after recanalization showed no sign of hemorrhagic transformation, but a right hemispheric swelling with midline shift and obstruction of the right lateral ventricle (Figure 1; C). A right decompressive craniectomy was performed 72 hours after MT because of persistent coma and radiological worsened (Figure 1; D). Patient's cardiac condition progressively improved, and VA-ECMO was removed on day 5. Due to delayed awakening, a tracheostomy was performed on day 15. Patient's neurological condition progressively improved, and cranioplasty was performed 3 months after craniectomy. The patient was finally weaned from his tracheostomy and transferred in a rehabilitation department. The patient was discharged home 2 years later; at that time his was walking without help and had a Rankin score of 2.

\section{DISCUSSION}

These cases illustrate the feasibility of performing MT on ECMO in adult patients ${ }^{6}$.

ECMO circuit is either in a VA or in a veno-venous (VV) configuration. It consists of a centrifugal pump, which provides a continuous flow in the circuit, and a membrane oxygenator that allow oxygenation and decarboxylation of the blood. In VA-ECMO, the circuit includes an inflow cannula which drains blood from the venous system, and an outflow cannula which delivers the warmed oxygenated blood back into the arterial system (Figure 2, A) in order to restore a circulatory flow in refractory cardiogenic shock and cardiac arrest. Intra-aortic balloon pump (IABP) is often added within the femoral artery in these patients (Figure 2, B) to protects against hydrostatic pulmonary edema 7 , or to improve coronary bypass graft flow and cardiac function in refractory postoperative cardiogenic shock 89 . It reduces left ventricular afterload, improves coronary perfusion, and provide pulsatile blood flow.

In VV-ECMO, the outflow cannula delivers oxygenated and decarboxylated blood to the vena cava and the right atrium (Figure 2, C), to insure a normal blood gas exchange during acute respiratory distress syndrome (ARDS) refractory to conventional therapy ${ }^{10}$.

Stroke occurs mainly during VA-ECMO ${ }^{311}$, whereas cerebral hemorrhage is mostly observed during VV-ECMO ${ }^{12}$. These complications have an important impact in terms of outcome.

In order to perform MT, the choice of the arterial vascular access to perform MT should be discussed with the bedside ECMO specialist in charge of the patient, depending on ECMO configuration. In our two cases, the femoral access opposite to the arterial inflow cannula was chosen, but transradial artery access is another option. As the patient receive continuous unfractioned heparin, it is mandatory to use vascular ultrasound during puncture to minimize complications. In both cases, no femoral IABP were implanted, but its presence should not contra-indicate MT, as the operator can perform the MT via transradial arteries. A particular situation, but rare in adult, is a VA-ECMO circuit configuration with outflow cannula delivering 
blood back into the axillary artery (Figure 2, D). In this case, the operator should not access transradial artery ipsilateral to the outflow cannula. In VV-ECMO configuration, all arterial access can be approached without constraint.

Concerning the timing of MT, our cases mainly differ, regarding the onset of the VA$\mathrm{ECMO}$, in relation to the neurological event.

In the first case, the neurological symptoms occurred suddenly after 5 days of VAECMO support in an alert patient, allowing us to determine precisely the stroke onset time. Unfortunately, patients under VA-ECMO are too often on invasive mechanical ventilation and heavily sedated, thus compromising neurological examination and stroke onset time determination. Although some patients need sedations many VA-ECMO patients remain sedated for the sole reason that they are under VA-ECMO, mainly for safety reasons. Fortunately, the recent literature goes against this dogma ${ }^{13}{ }^{14}$, and patients are lightly sedated, or extubated when possible, giving the opportunity to have proper neurological evaluation.

For the second case, the timing was different: immediately after a coronary angiography, he presented sudden neurological symptoms suggestive of cerebral infarction, probably of cardioembolic origin, related to atherosclerotic material release out of vascular plaques in the setting of coronary angiography ${ }^{15}$. Due to the initial presentation with refractory cardiogenic shock, the first step was to restore respiratory and hemodynamic compromises using oro-tracheal intubation and mechanical ventilation, catecholamine infusion and VA-ECMO insertion. Even if it delayed the management of the stroke (6.5 hours were needed to perform this sequence, although all human and technical resources were available on site), the patient was finally transferred to the radiology department, where CT scan, CTA and MT were performed. For this latter case, the evolution differed from that of our first case mainly because the former had too late MT, complicated with brain infarction and brain swelling requiring hemicraniectomy. However, significant neurologic recovery was finally observed in this patient.

In both cases, the main point that was debated was about performing or not an MT: indeed, VA-ECMO usually requires continuous infusion of unfractioned heparin to avoid circuit thrombosis and/or thrombo-embolic events, which in our cases had to be counterbalanced with the risk of reperfusion syndrome occurrence with secondary hemorrhagic transformation after MT. Indeed, it is not known whether VA-ECMO increases the risk of MT-induced cerebral hemorrhage, and if we refer to the literature, the only published case of IAMT on ECMO has been reported by Sun et al 16, in a 9-month-old infant under VA-ECMO, inserted for cardiovascular collapse after parainfluenza pulmonary infection associated with acute cor pulmonale. In this case report, the infant developed both left MCA and basilar artery occlusions. MT could only have been performed within the posterior circulation, with a successful result, and without secondary hemorrhagic transformation. Finally, poor clinical outcome was observed, due to a large intracerebral hemorrhage in the left MCA territory. Together, these three cases suggest MT safety under ECMO support, although further studies are needed to determine the precise risk of secondary hemorrhagic transformation after IAMT in this specific population. 


\title{
LEARNING POINTS/TAKE HOME MESSAGES
}

\author{
- MT feasibility on ECMO \\ - Light sedation/extubation when possible in order to have proper neurological \\ evaluation and stroke onset time determination.
}

\section{FIGURES}

Figure 1: Cerebral digital subtraction angiography of the right internal carotid artery in antero-posterior projection (second case) showing a right middle cerebral artery occlusion (white arrow) (A) before, and (B) after recanalization. (C) CT-scan performed at day 1 shows a large ischemic infarct despite recanalization, with a right hemispheric swelling, midline shift and collapsus of the right lateral ventricle. CT scan with volume rendering reconstruction (D) after the right decompressive craniectomy was performed.

Figure 2: ECMO circuits

(A) Femoro-femoral VA-ECMO circuit (B) Femoro-femoral VA-ECMO circuit with controlateral IAPB (C) Femoro-jugular VV-ECMO circuit (D) Femoro-axillary VA-ECMO circuit

ECMO; extracorporeal membrane oxygenation

$\mathrm{VA}$; venoarterial

$\mathrm{VV}$; venovenous

IAPB; Intra-aortic balloon pump

\section{REFERENCES}

1. Dangers L, Brechot N, Schmidt M, et al. Extracorporeal Membrane Oxygenation for Acute Decompensated Heart Failure. Crit Care Med 2017;45(8):1359-66. doi: 10.097/CCM.0000000000002485.

2. Hekimian G, Kharcha F, Brechot N, et al. Extracorporeal membrane oxygenation for pheochromocytoma-induced cardiogenic shock. Ann Intensive Care 2016;6(1): 117. doi: 10.1186/s13613-016-0219-4. Epub 2016 Nov 28.

3. Le Guennec L, Cholet $C$, Huang $F$, et al. Ischemic and hemorrhagic brain injury during venoarterial-extracorporeal membrane oxygenation. Ann Intensive Care 2018;8(1):129. doi: 10.1186/s13613-018-0475-6.

4. Le Guennec L, Bertrand A, Laurent C, et al. Diffuse cerebral microbleeds after extracorporeal membrane oxygenation support. Am J Respir Crit Care Med 2015;191(5):594-6. doi: 10.1164/rccm.201411-2118LE.

5. Luyt CE, Brechot N, Demondion $P$, et al. Brain injury during venovenous extracorporeal membrane oxygenation. Intensive Care Med 2016;42(5): 897-907. doi: 10.1007/s00134-016-4318-3. Epub 2016 Mar 23.

6. Premat K, Clovet O, Frasca Polara G, et al. Mechanical Thrombectomy in Perioperative Strokes: A Case-Control Study. Stroke 2017;48(11):3149-51. doi: 10.1161/STROKEAHA.117.018033. Epub 2017 Oct 10.

7. Brechot N, Demondion $P$, Santi F, et al. Intra-aortic balloon pump protects against hydrostatic pulmonary oedema during peripheral venoarterial-extracorporeal membrane oxygenation. Eur Heart J Acute Cardiovasc Care 2018;7(1):62-69. doi: 10.1177/2048872617711169. Epub 2017 Jun 2.

8. Madershahian N, Wippermann J, Liakopoulos 0 , et al. The acute effect of IABPinduced pulsatility on coronary vascular resistance and graft flow in critical ill patients during ECMO. J Cardiovasc Surg (Torino) 2011;52(3):411-8. 
9. Madershahian N, Liakopoulos OJ, Wippermann J, et al. The impact of intraaortic balloon counterpulsation on bypass graft flow in patients with peripheral ECMO. J Card Surg 2009;24(3):265-8. doi: 10.1111/j.540-8191.2009.00807.x.

10. Combes A, Hajage D, Capellier G, et al. Extracorporeal Membrane Oxygenation for Severe Acute Respiratory Distress Syndrome. N Engl J Med 2018;378(21): 1965-75. doi: 10.056/NEJMoa1800385.

11. Risnes I, Wagner K, Nome T, et al. Cerebral outcome in adult patients treated with extracorporeal membrane oxygenation. Ann Thorac Surg 2006;81(4):1401-6. doi: 10.1016/j.athoracsur.2005.10.008 [published Online First: 2006/03/28]

12. Luyt $\mathrm{CE}$, Brechot $\mathrm{N}$, Demondion $\mathrm{P}$, et al. Brain injury during venovenous extracorporeal membrane oxygenation. Intensive Care Med 2016;23:23.

13. Ellouze 0 , Lamirel J, Perrot J, et al. Extubation of patients undergoing extracorporeal life support. A retrospective study. Perfusion 2019;34(1):50-57. doi: 10.1177/0267659118791072. Epub 2018 Jul 25.

14. Shekar K, Grewal J, Lisa Sutt A, et al. Individualizing Sedation in Acute Respiratory Distress Syndrome Patients on Extracorporeal Membrane Oxygenation. Asaio J 2019;65(4):e44-e45. doi: 10.1097/MAT.0000000000000969.

15. Werner N, Zahn R, Zeymer U. Stroke in patients undergoing coronary angiography and percutaneous coronary intervention: incidence, predictors, outcome and therapeutic options. Expert Rev Cardiovasc Ther 2012;10(10):1297-305. doi: 10.586/erc.12.78.

16. Sun LR, Pearl M, Bahouth MN, et al. Mechanical Thrombectomy in an Infant With Acute Embolic Stroke. Pediatr Neurol 2018;82:53-54.(doi):10.1016/ j.pediatrneurol.2018.02.002. Epub 18 Feb 14. 